\title{
The Road Toward Tenure
}

\author{
Judith Ableser Ph.D., University of Michigan-Flint, USA
}

\begin{abstract}
This paper/presentation outlines a "top ten list" of key strategies that will aid in the tenure process for new faculty members. Research and focus group comments are interwoven with the experiences of one faculty member. The strategies described include; integrating teaching, research and service, learning the culture and politics, organization, devoted time to research and planning, focusing on your passions, setting goals, setting high standards, learning from others, prioritizing and balancing, and celebrating your accomplishments. As one begins an academic career, the thought of earning tenure can be daunting and overwhelming, yet by approaching it as a planned journey, one can enjoy the road along the way and celebrate the destination. In September, 2008 I earned tenure. The purpose of this paper is to provide insight into the steps and strategies that guided me during my process. Although I will cite recommendations outlined by the American Association of University Professors (AAUP), the American Council on Education (ACE) and other research (Boyer, 1990; Bradley, 2005; Caesar, 2004; DeGeorge, 1997; Fox, 2006; Holly 1977; Mullen, 2000; Ward, 2004; Sotello, 2000; Zellers, 2006), my intent is primarily to share my own experiences. I will contrast this with conversations I have had with other colleagues during focus group discussions to demonstrate that we must each follow our own path to arrive at our destination. Hopefully, this will assist you as you plan your journey. But please note that this is what worked for me. Do not follow my precise path; I encourage you to set your own course. Know where you are headed and plan, intentionally and deliberately, to ensure that you will not only be successful in reaching your destination but to grow and develop throughout the entire journey.
\end{abstract}

Keywords: Tenure, Teaching, Research, Service

\section{INTEGRATE TEACHING, SERVICE AND RESEARCH}

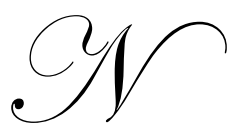

ew professors are often overwhelmed when they are first hired and realize that they must balance teaching, research and service. Many students naively think their professors' role is to teach only a few courses each semester and are not aware of the inordinate time and professional commitment devoted to research and service. New professors are frequently surprised by this reality as well. What I found to work well for me was to integrate all three. This not only assisted me with my time management but enhanced my professional philosophy, pedagogy and practice. This aligns with Boyer's (1990) model of "Scholarship Reconsidered" in which he argues that scholarship must change to meet the educational needs of the $21^{\text {st }}$ century by focusing on the scholarship of teaching, active learning, service learning and critical thinking.

My areas of expertise are in special education and literacy. In my courses, I focus on teaching ways to engage struggling readers and writers in the writing process. My initial community service was to develop and implement "An Inclusive Young Authors Program" involving students with special needs in the local schools. I included my own teacher candidates in the classrooms to assist with the implementation of the program. I received a Research Excellent Grant and engaged in research on my work, publishing three articles and presenting at numerous conferences.

Colleagues in other fields, such as nursing, science, engineering and business, have shared similar stories of how they have successfully integrated all three areas and have agreed that this has made for much more efficient and effective time management, as well as a more integrated approach to their work. 


\section{LEARN THE CULTURE AND POLITICS...BUT AVOID GETTING PULLED INTO THE POLITICS}

One of the most important and challenging things when you first come to any new institution is to learn the system, culture and politics. This takes time, but is critically important. Observe, listen, listen more, and ask questions.

I have learned from my own mistakes. Prior to coming to my current position, I was at another university where I was not aware of the internal politics. I unfortunately got swallowed up by the infighting between senior faculty and management. I did not have the experience or insight to realize what was really at play was the hidden agendas and academic politics.

It is vitally important to feel free to speak up and take a stand on issues (even as new untenured faculty), but it is important to know the system, and understand the interpersonal and political dynamics at play. It is helpful to find those who can provide support and mentorship from the first moment we walk through the door (Mullen, 2000; Sotello, 2000; Zellers, 2006) and with whom we can collaborate throughout our career. In any large organization you will find the two categories of individuals: The door openers and the door closers. The door openers are those who are there to guide and support you and the institution at large. They are the facilitators, mentors, visionaries, organizers, welcomers, critical thinkers, and collaborators. The door closers are the blockers, bullies, intimidators, back stabbers, gossipers, manipulators, blamers, and control freaks. Every large institution has their share of both. We need to recognize early on who is in each category and align ourselves with those that can support and enhance our own growth and the growth of the overall university. It is, however, equally important to learn to work carefully with the other group. As the old saying goes; "keep your friends close and your enemies closer".

\section{ORGANIZATION- TIME, SYLLABUS, COURSE OBJECTIVES, LESSONS}

For me, the more organized I am, the more secure I feel. In addition, I find that my students truly appreciate my organization and comment on it in my course evaluations. As professors, we all have our own style of organization (Caesar, 2004) and it often reflects who we are. I will highlight a few examples of my organization.

I provide a very detailed syllabus with all assignments and marking rubrics during the first class. Although students may initially feel overwhelmed when they see all that needs to be accomplished, the vast majority thank me for helping them know up front exactly what is expected of them. I encourage them to transcribe the course sequence and due dates into their own day planners so they can effectively plan their entire semester.

I use Blackboard, our on-line system, a great deal. I prefer to teach all my courses in a mixed mode format whereby I meet with my students every other week. One of the benefits of Blackboard is that I can set up all documents, power points, articles, videos, discussion board, assignments and announcements prior to the beginning of the course and set it on "time release" to appear as needed. This way, I can focus my time on responding to the discussion boards, marking the assignments and modifying announcements and documents as needed on a day-today basis.

\section{BLOCK OF TIME DEVOTED FOR PLANNING AND RESEARCH}

Research in higher education continues to play a critical and vital role in both our own tenure process and the central purpose of most academic institutions (AAUP, 2006; ACE, 2005; Holly; 1977). I have found that it is imperative to set blocks of times to engage in my research. I commute over 150 miles round trip to my university and was a bit nervous when I accepted this position. Although I am on campus on a regular basis, I knew that I would not be in my office on a daily basis as I had been in my previous position. Initially, I was concerned about not having the time to accomplish my work due to my commute, but the truth of the matter is that I have found that I am far more productive than I was when my office was five minutes away. In my previous position, I would have so many distractions while in my office that it was difficult to get work done. I now find that I can devote large "chunks" of uninterrupted time at home to my planning and research. 
Other colleagues I have spoken with say that they too use "blocks" of time to write and do their research. A number have indicated that they cannot write during the fall/winter semesters while they are teaching but find that they are successful during the summer when they can go to a cottage or "quiet" place and can work for an extended block of time. In contrast, however, other colleagues adamantly state they never bring their work home and prefer to come into the office on weekends or stay late at night to do their writing. They feel it is essential for their own mental health, and the health of their families, to keep their work and personal life very separate.

\section{PASSION-- DO WHAT YOU LOVE, LOVE WHAT YOU DO--CELEBRATE WHAT YOU DO BEST.}

The professional demand on our time in most institutions is great. Due to cutbacks and constraints, we constantly seem to be expected to do more with less. If at all possible, select the type of service at which you excel. We are not all good at the same things nor should all of us have to serve on every committee and be involved in all tasks. But we can all have expertise, interests and passions (Boyer, 1990) and should have the courage and conviction to embrace those roles to which we can contribute effectively, while learning to say "no" at other times.

When I have been asked to serve on committees, I select ones in which I feel I can contribute and am interested. There are many areas that are not my expertise or require skills that I do not have. I want to use my time and the time of my colleagues efficiently. . I want to ensure that I am a valued contributor and do not want to "burn out". I have learned not to volunteer and even to say "no" when asked. Do not serve simply to add another committee on your c.v.

\section{SET GOALS AND GROWTH FOR YOUR TENURE PROCESS FROM THE START}

Every institution, in fact, each faculty or department may have different expectations for tenure (AAUP, 2006; ACE, 2005; Boyer, 1990). Research One universities obviously focus more emphasis on obtaining grants and engaging in research. Other institutions place far more emphasis on teaching. Some faculties may even provide guidelines of $40 \%$ teaching $+40 \%$ research and $20 \%$ service. Many have written guidelines and clear expectations consistently followed for tenure while others do not. As soon as you are hired, find out from your Dean what your expectations are regarding your teaching/service/research. If possible, have these expectations outlined in written form, including a clear timeline and what is expected for annual reviews.

As a general rule of thumb, I have found the following timeline to be effective for me and other new faculty in planning the tenure journey. During the first year, focus on your teaching, learning the culture, and developing a research agenda. If you have just completed your $\mathrm{PhD}$, use this time to write and publish at least one article from your dissertation. During your second year, continue to develop your teaching, engage in research, present at conferences, publish, and provide service at the unit/department level. In your third year, continue the above and add service to the profession/community. In the fourth year, involve yourself in some university level service. Finally, in your fifth year, continue to expand and develop all these areas as you finalize your tenure documents.

\section{SET HIGH STANDARDS FOR YOURSELF AND YOUR STUDENTS.}

I believe that our teaching and expectations of our students should be of the highest standards, however, I believe strongly that it is up to us to support and guide them to meet those standards. I was an adult mature student when I went back to get my $\mathrm{PhD}$. so I try to model what I felt was supportive, respectful behavior toward diverse students. Because I want all my students to succeed, I feel it is my responsibility to ensure that I provide the support and guidance for them to do so. As I stated previously, I provide a marking rubric with all my assignments so that students know exactly what they need to do in order to earn the marks. I have found that since doing this, my students' level of success is much higher, because they know exactly what is expected of them. In addition, I rarely have a student challenge me on a grade because the rubric clearly demonstrates how they earn each mark. As I believe in a mastery learning and process approach, I allow for revisions and rewrites on my assignments. During my first semester, I was disappointed in the lack of research and writing skills that my students demonstrated. From that point on, I have provided a research and APA workshop to any student who would like to take it. If I expect high standards, I feel I must provide the support for my students to meet those standards. 
Some colleagues hold very different beliefs and practices regarding student success and mastery and might view my position as "spoon feeding" or "coddling" my students. But for me, based on my philosophy of teaching, I find this to be the best way for my students to successfully meet my high standards. Similarly, I believe that we must set high standards for ourselves as professionals and academics, and in order to meet those standards, we must allow ourselves to get the help and guidance we need as well. We must learn to ask for guidance and welcome suggestions and recommendations for growth. We must seek out those "door openers" who will support us through the journey.

\section{LEARN FROM YOUR STUDENTS, COLLEAGUES, AND FROM YOUR OWN MISTAKES}

I teach about and do research on the "collaborative consultation model" in special education (Dettmer, 2005). This model stresses that all stakeholders/members of teams bring their own expertise, knowledge and experience to the table in order to collaboratively problem solve. I feel that we do learn from each other. We should all learn from our colleagues, our students and ourselves. In our department, we observe other faculty members as they teach. In reality, it is to provide "observational assessments" for their tenure portfolio. I find, however, that as an observer, I learn from them and incorporate their strategies into my own teaching. In follow up discussion, I too, can reflect on my own teaching and discuss concerns and issues that I may have about my own experiences.

I know I learn from my students. In my previous role, in addition to teaching, I supervised student teachers in the field. I felt that this kept me current and "honest" about what was actually going on in the field. In my current position, apart from my research, I rarely have the opportunity to be out in the schools on a regular basis. In all of my courses, the major assignment involves students going into schools to complete an analysis of some aspect by linking theory with practice/observation. By doing this, not only are they learning valuable lessons, but I, too, am learning from them.

Finally, I analyze my own mistakes and reflect upon what I could do to improve my teaching or communication. Mistakes truly are "opportunities for growth" if we allow ourselves to view them as such.

\section{BALANCE, PRIORITIZE, FOCUS}

Along with balancing teaching, research and service, we must add in balancing our professional life with our personal life. This is one of the most controversial and debated areas currently within academia. Numerous policies, recommendations and much research have recently been developed on the need to establish more familyfriendly, life-balanced, flexible tenure-track streams (ACE, 2005; Bradley, 2005; Fox, 2006; Ward, 2004). We all have different demands on our lives and are at different points in our lives. Each of us has different demands due to different life circumstances and we must respect those differences. I am able to work at home because I have few distractions. I do not have the demands of having young children or being newly married or caring for an aging parent. I know that I could not have been this productive years ago, nor should I have been. We must prioritize what really matters in our lives and find the time for life outside of work. For each of us this looks very different based on our own personal needs and style. For example, I check my email frequently seven days a week, when I am at home and even when I am away on holidays because I find it reduces my stress to do a little bit at a time. Other colleagues feel that they do not want to bring their work home with them and choose not to check their email outside of work. There is no one way, nor is there one right way. We do what works best for us to balance our own lives.

\section{CELEBRATE YOUR ACCOMPLISHMENTS}

We all work hard every day, yet we rarely stop and celebrate what we do and what we have accomplished. To me, this is actually one of the joys of the journey toward tenure. We have the opportunity to reflect on what we have done. Do not leave collecting all your tenure portfolio documentation to the last year. It will be daunting. As soon as you are hired, collect all your work into annual folders (teaching, research, service), write summaries, narratives and reflections each year along with updating your c.v. Review your work each year and plan your next 
steps and future goals. Then during the final year, select what you feel best demonstrates the very best that you are. Not only does it make the process much easier, it truly allows you to celebrate what you have accomplished.

I hope my Top Ten List has helped you. I hope I am one of your "door openers". But do not just follow my path. Follow your own. Find what works for you and do it. Change what doesn't work for you. Enjoy the journey and celebrate your work and accomplishments. You have earned it. Good luck to you all.

\section{AUTHOR INFORMATION}

Judith Ableser Ph.D. is an Associate Professor at the University of Michigan-Flint. She is the Director of Graduate Programs in Education and the Co-ordinator of Special Education. Her areas of expertise include Special Education, Literacy, Elementary, Early Childhood and Teacher Education.

\section{REFERENCES}

1. American Council on Education (2005) An agenda for excellence: Creating flexibility in tenure-track faculty careers. ACE

2. American Association of University Professors (2006) Recommended Institutional Regulations on Academic Freedom and Tenure AAUP

3. Boyer, E (1990) Scholarship Reconsidered The Carnegie Foundation for the Advancement of Teaching: New Jersey

4. Bradley, G. (2005) "Recommendations issued on work-life balance" Academe May-June 2005

5. Caesar, T. (2004) "Trading spaces: The faculty office in cross culture perspective" Academe Jan-Feb 2004, 16-19.

6. Fox. G; Schwarta, A; Hart, K. (2006) "Work-Family Balance and Academic Achievement in Medical Schools" Academic Psychiatry vol.30 May-June 2006 227-234.

7. DeGeorge, R (1997) Academic Freedom and Tenure: Ethical Issues Rowman and Littefield

8. Dettmer, P.; Thurston, L., Dyck, N. (2005) Consultation, collaboration and teamwork Pearson: New York.

9. Holly, J. (1977) “Tenure and Research Productivity” Research in Higher Education vol 6(2) June 1977, 181-192.

10. Mullen, C; Fobes, S. (2000) "Untenured Faculty: issues of transition, adjustment and mentorship" Mentoring and Tutoring: Partnerships in Learning vol8 (1) April 2000, 31-46.

11. Sotello Viernes Turner, C (2000) New faces: New knowledge" Academe Sept-Oct. 2000

12. Ward, K; Wolf-Wendel, K. (2004) "Fear Factor: How safe is it to make time for the family" Academe Vol90(6) Nov-Dec. 2004

13. Zellers, D (2006) "Mentoring and support through your whole career" Academe v92(6) 
NOTES 